\title{
THE USE OF A BUILDING INFORMATION MODEL TO SUPPORT SEISMIC ANALYSIS: APPLICATION TO THE NATIONAL PALACE OF SINTRA, PORTUGAL
}

\author{
M. PONTE ${ }^{1}$, R. BENTO ${ }^{1 *}$, R. MACHETE ${ }^{1}$, M. GODINHO ${ }^{1}$, A. B. GONÇALVES ${ }^{1}$ AND \\ A.P. FALCÃO ${ }^{1}$ \\ ${ }^{1}$ Civil Engineering Research and Innovation for Sustainability (CERIS) \\ Instituto Superior Técnico, Universidade de Lisboa \\ Av. Rovisco Pais, 1049-001 Lisboa, Portugal \\ e-mail: \{madalenaponte, rita.bento, rita.f.machete\}@tecnico.ulisboa.pt, marcia.godinho@gmail.com, \\ \{alexandre.goncalves, ana.p.falcao\}@tecnico.ulisboa.pt \\ (*corresponding author)
}

Keywords: Historical Masonry Buildings, Laser Scanning, H-BIM, Seismic Analysis, Sintra National Palace

\begin{abstract}
This work presents an application of a Building Information Model (BIM) to the National Palace of Sintra, Portugal, a large and complex building composed of different unreinforced masonry buildings that is included in the Cultural Landscape of Sintra, classified under the UNESCO World Heritage list in 1995. The developed H-BIM (Heritage Building Information Modelling) model has the ability to provide the geometric information of the structure of the building, together with its descriptive attributes, such as the mechanical characterization of the building materials, as inputs to the seismic structural analysis. The results of such analyses are also stored as attributes within the H-BIM model, providing an integrated platform usable by the building management. Geometric data was acquired using a Faro Focus ${ }^{S}$ 70, together with a Topcon Falcon 8+UAV. The methodology applied in the

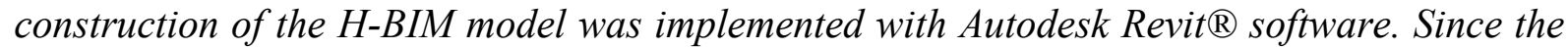
Palace is very complex, its seismic behaviour was studied for the different building units, considering the effect of the adjacent ones, and performing nonlinear static analyses through 3Muri software.
\end{abstract}

\section{INTRODUCTION}

Built Cultural Heritage $(\mathrm{CH})$ sites represent a high value in the definition of cultural identity and it is therefore of the utmost importance to have resources and tools to efficiently support their maintenance and safety. The conservation of buildings' architectural heritage and its maintenance and management are complex tasks since they are the result of historical events, different architectural influences, changes in ownership, and transformations over time [1]. In order to document the important aspects related to the maintenance and conservation of $\mathrm{CH}$ buildings or sites, the existence of a complete and coherent database, preserving data of complex systems and capable of answering requests for information demand, is strategic.

The BIM process is well established for new constructions, but not for existing ones, in 
particular for $\mathrm{CH}$ buildings. For the latter, its implementation faces several problems or challenges such as: the predominance of incomplete or fragmented building information; the complex geometry of most buildings: the need to set up a geometric model that adapts to the parametric representation used by most BIM tools; and the need to represent historical changes in the buildings [2]. In addition, any BIM implementation in the built $\mathrm{CH}$ context is strongly related with the purpose for which it has been developed, thus including specificities and capabilities related with the normal maintenance, historical assets, or support for specific studies, for which a multidisciplinary approach is mandatory.

In this paper, a methodology for a BIM-based system implementation for the National Palace of Sintra (Figure 1), in Portugal, is described. The National Palace of Sintra is the most important building in the town centre and one of the most visited palaces in Portugal. It was the royal dwelling of the Portuguese royalty and its value is immeasurable. Given its cultural and social importance, there is undoubtedly the need for its preservation and documentation.

The acquisition of the material properties employed several in situ experimental tests ground-penetration radar (GPR), masonry samples collection, flat-jack tests, ambient vibration tests - as the palace was built using different materials along with its construction from the 11 th to early 20 th centuries. The experimental results were used to evaluate the structural condition of the palace and to assess its structural safety level, allowing for fine tuning of the strengthening and rehabilitation interventions.

The completed operational model constitutes a useful tool to spatially reference the various tests and essays that are being conducted in the palace adequate structural models a BIM database.

The Chapel (Figure the procedures followed
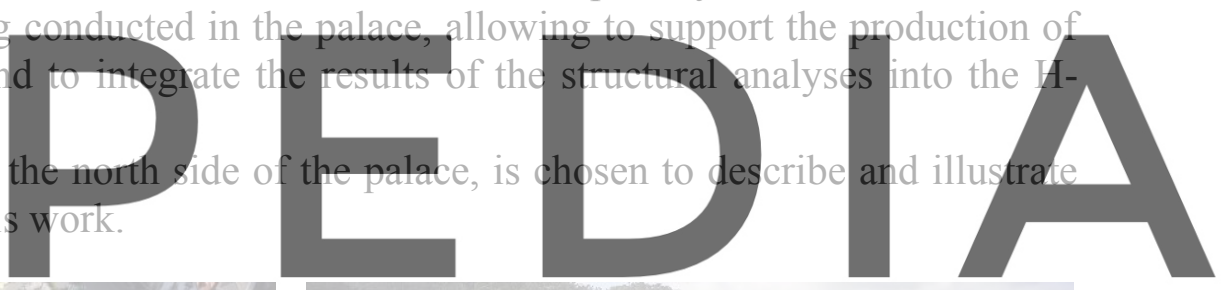

Register for free at https//www.scipedia.com to

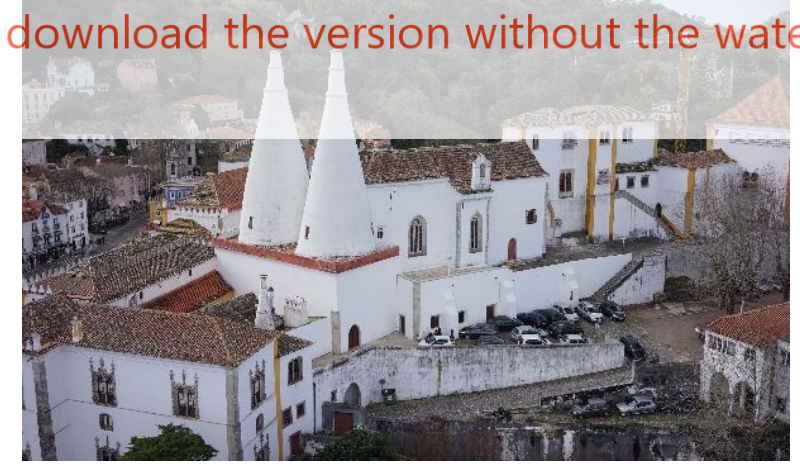

Figure 1: A top view of the National Palace of Sintra (left); The north view of the palace with the chapel on the right side of the chimneys (right)

\section{H-BIM OF NATIONAL PALACE OF SINTRA - METHODOLOGY}

\subsection{General Description}

For the development of the H-BIM model [3], three main steps are highlighted, as 
schematically represented in Figure 2. Firstly, the geometry of the palace was acquired with a combination of terrestrial laser scanning (TLS) and unmanned aerial vehicle (UAV) techniques, covering the 11 levels of the palace, which correspond to 244 spaces (e.g. rooms, outdoor gardens, patios) and surrounding environment locations. The two-point clouds datasets were combined into a single coherent H-BIM model and modelled using the Autodesk Revit ${ }^{\circledR}$ software, enabling its conversion to individual surfaces and objects. This model served later as a basis for the construction of the numerical model used in the seismic assessment.

In the H-BIM model, it is possible to include a miscellany of attributes, graphic and nongraphic, with capabilities to represent descriptive characteristics, updated whenever necessary. Some of the attributes may even come from the seismic assessment, such as the identification of the walls vulnerable to the seismic action, and others from the experimental tests. The detailed description of the different steps is provided in the following sections for the Chapel case study.

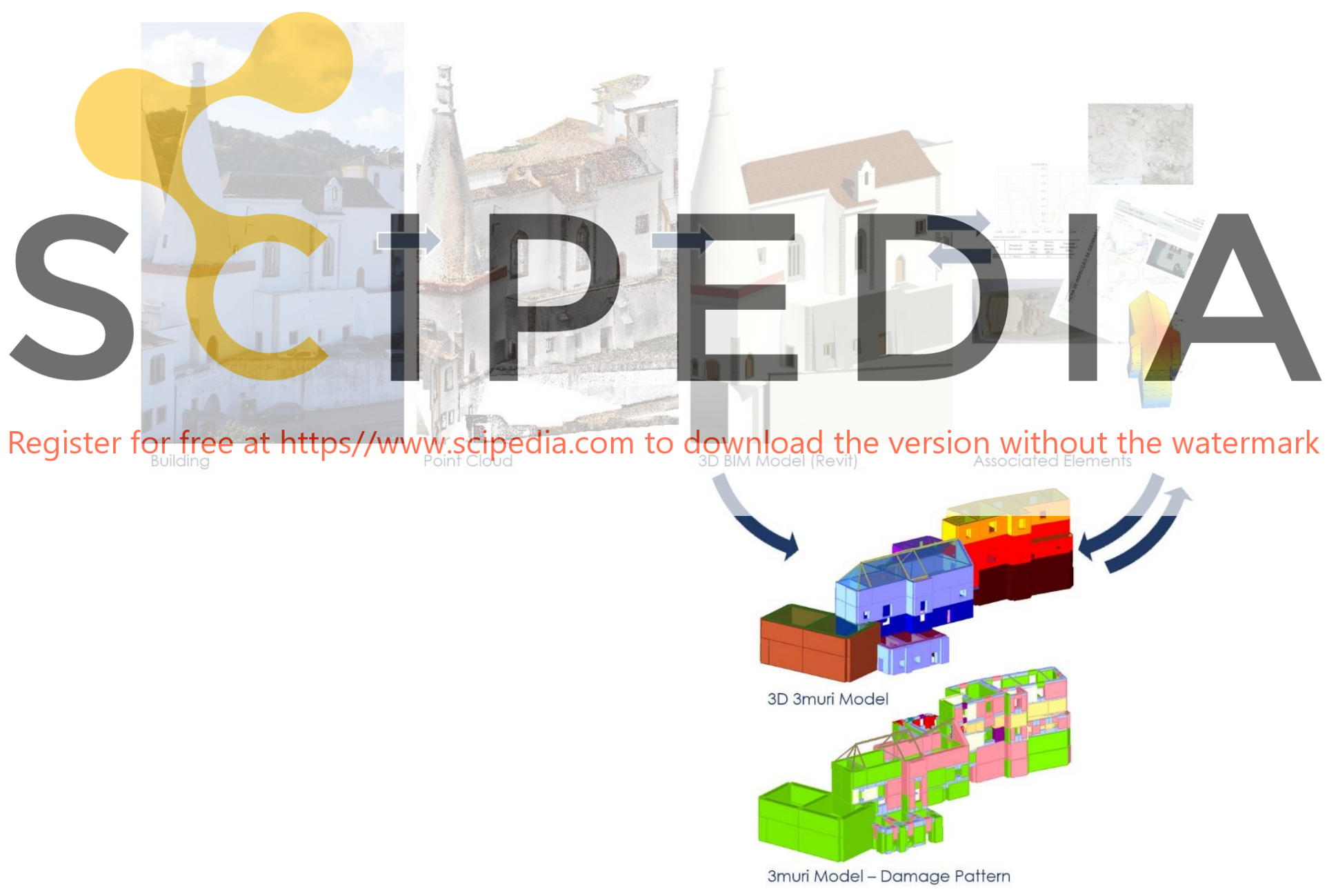

Figure 2: Main steps of H-BIM development process applied to the Chapel

The palace is composed of several connected buildings that were built along the centuries. 
Due to the large scale of the monument, the H-BIM model is divided into the main bodies of the palace, thus keeping a reasonable model size. One of the challenges in such complex and culturally important structures is to define the equilibrium between the maximum quality level required versus the time spent and the data size. This problem can appear either while collecting scans or setting up the Revit model.

\subsection{National Palace of Sintra}

The National Palace of Sintra is a complex structure composed of several masonry buildings, and one of the oldest existing palaces in Portugal, based on Arab foundations. The palace has a special presence in the cultural landscape of the village of Sintra, classified as a World Heritage Site by UNESCO in 1995, mainly due to its two iconic chimneys. In a mixture of Arab and Christian cultures, the construction of the palace has evolved over several ages, becoming one of the rare medieval palaces that have reached our times practically intact, preserving its authenticity. It survived the 1755 earthquake, although small parts were required to be rebuilt at the time, and the 1969 earthquake, which caused some visible damage and floors' settlements in the Bonet building (belonging to the oldest part of the palace).

The Chapel, on the north side of the palace, is chosen to describe and illustrate the procedures that were followed. This chapel still survives today and is one of the oldest parts of the palace $\left(13^{\text {th }}-14^{\text {th }}\right.$ centuries). The palace chapel has a tiled floor, walls painted in
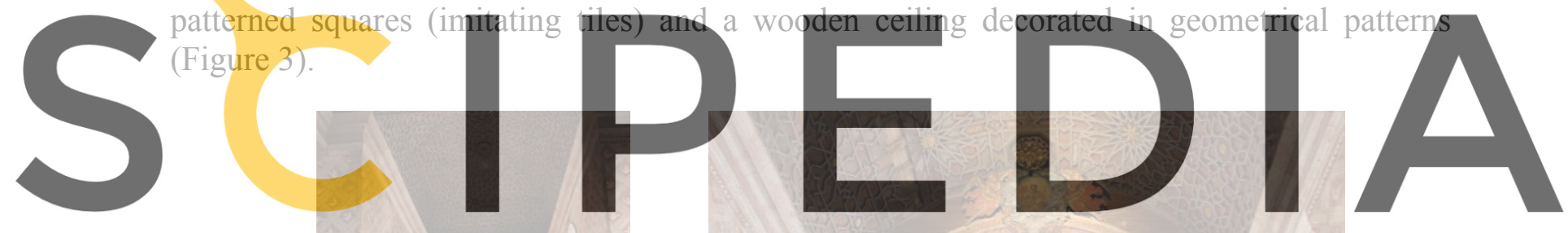

Register for free at https//www.scipedia.com to download the version without the watermark
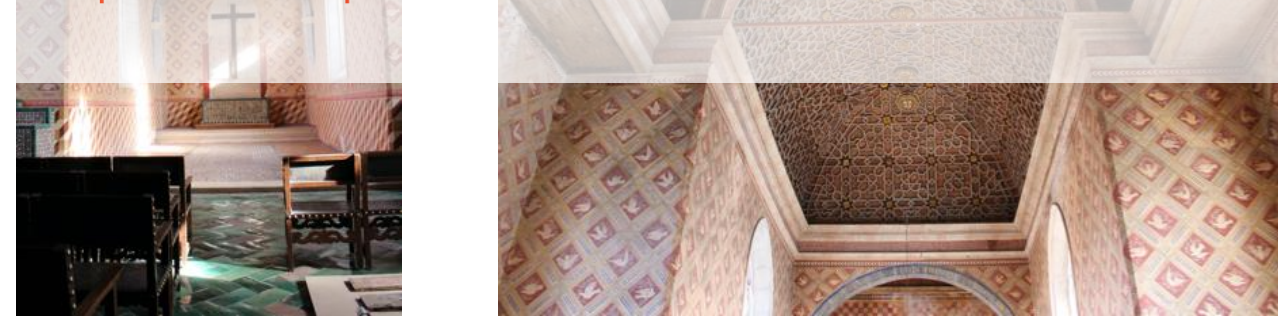

Figure 3: Interior of the Chapel: tiled floor, painted walls and the wooden ceiling

\subsection{Data Acquisition}

The main aim of this work was to develop an H-BIM model that facilitates spatial reading and a database that is able to include a variety of attributes with capabilities to represent a different type of characteristics, with a large application within heritage management and conservation activities. Requisites were defined to include, beyond the geometry, attribute data to assign to each model element. Attributes that can be assigned are of various types, e.g. historical documentation, the description of materials, construction stages, structural analysis, 
other technological aspects, and other information from other inspections, such as experimental in situ tests. Thus, two main types of data can be stored or linked to the H-BIM model: geometrical and attribute data.

\section{Geometrical Data}

The geometrical survey of the entire palace was performed using a Faro Focus ${ }^{\mathrm{S}} 70$ and a Topcon Falcon 8+ UAV (Figure 4).

Laser Scanner Faro S70

$(1 \mathrm{~mm} / 70 \mathrm{~m})$

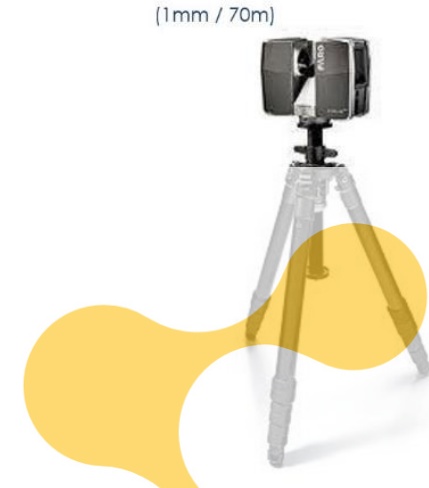

UAV Falcon 8+

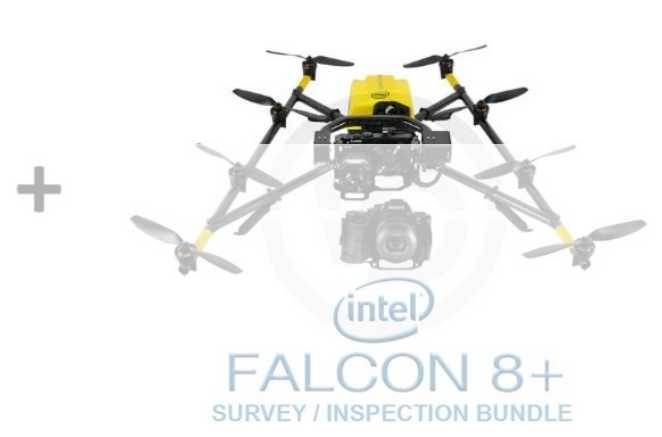

Point Cloud

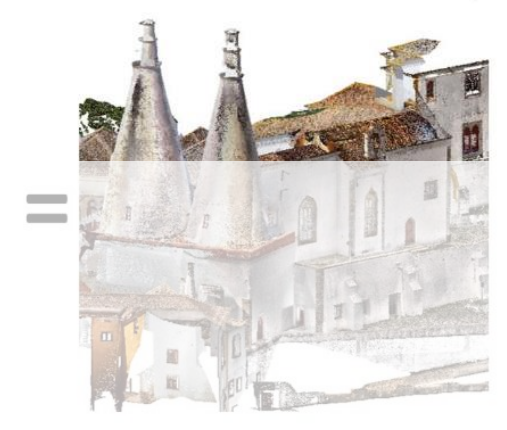

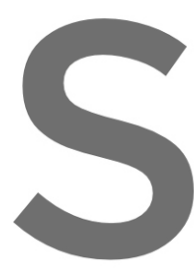

Figure 4: Equipment used

A total of 1397 scans and 17

indoors and outdoors, a
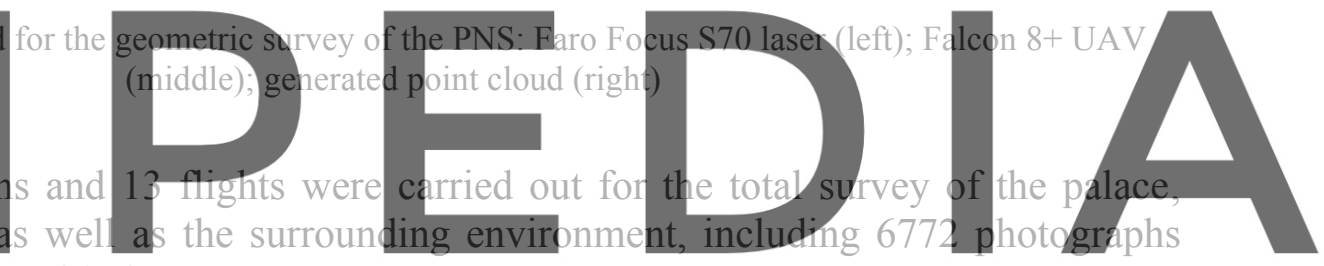

collected, of which 1478 with the UAV.

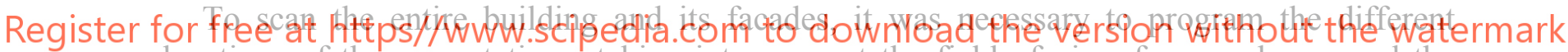

locations of the scan stations, taking into account the field of view from each one and the

necessary overlap with previous and following stations, in order to enable the 3D geometry

reconstruction. In the following stage of the process, named co-registration, the point clouds of successive scans are combined into a coherent coordinate reference system through the identification of homologous features (e.g. corner points of architectural objects, plans, marks or checkerboard registration marks) between scans. From the imported point clouds, all the walls, floor, ceiling, columns, doors, windows and other significant elements of architecture were built as BIM elements using plane fitting, or, in the case of the more complex geometries, using parametric modelling where an adequate level of simplification was established.

For the acquisition of outdoor data, namely roofs, terraces, the highest areas of the facades and gardens, the UAV was used (Figure 5) to provide a point cloud produced using photogrammetric processing techniques. 

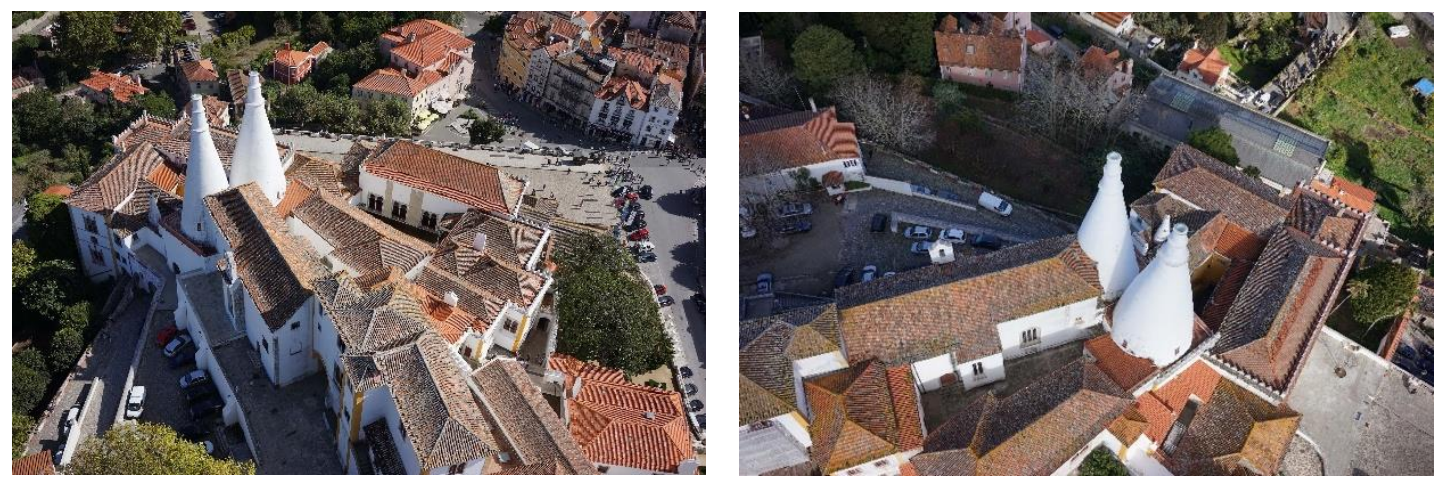

Figure 5: Aerial photograph of the parts of the palace (including the Chapel) collected by the UAV.

\section{Attributes}

Historical attributes were filled with information describing the history of each space (such as the rooms, staircases, halls and passageways) or each individual constitutive element (e.g. wall), and its original and current uses. Management attributes record information related to interventions in the building, such as the type of facility or the chronology of the works. Images, text documents and spreadsheet files were the most common data formats in both cases.

To evaluate the seismic safety of the palace and to identify possible structural anomalies and vulnerability factors, an interdisciplinary methodology was developed [4] including an in situ experimental campaign. In the framework of the approach described in [5], allowing for an adequate characterization of the structural properties, different types conducted, considering Semi-Destructive and Non-Destructive Test respectively): removal tests (NDT) and Ground-Penetrating Radar (CP very useful data have been obtained to define and calibrate the structural numerical models

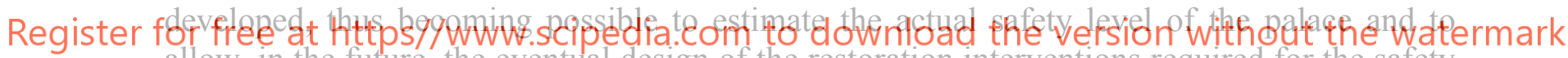
allow, in the future, the eventual design of the restoration interventions required for the safety of the historical construction.

The locations of the removal of masonry samples, flat-jack tests, ambient vibration tests and GPR tests were defined and represented in the BIM model (Figure 6 and Figure 7). All the main results obtained with experimental in situ are linked to the model or added to it as attributes. 


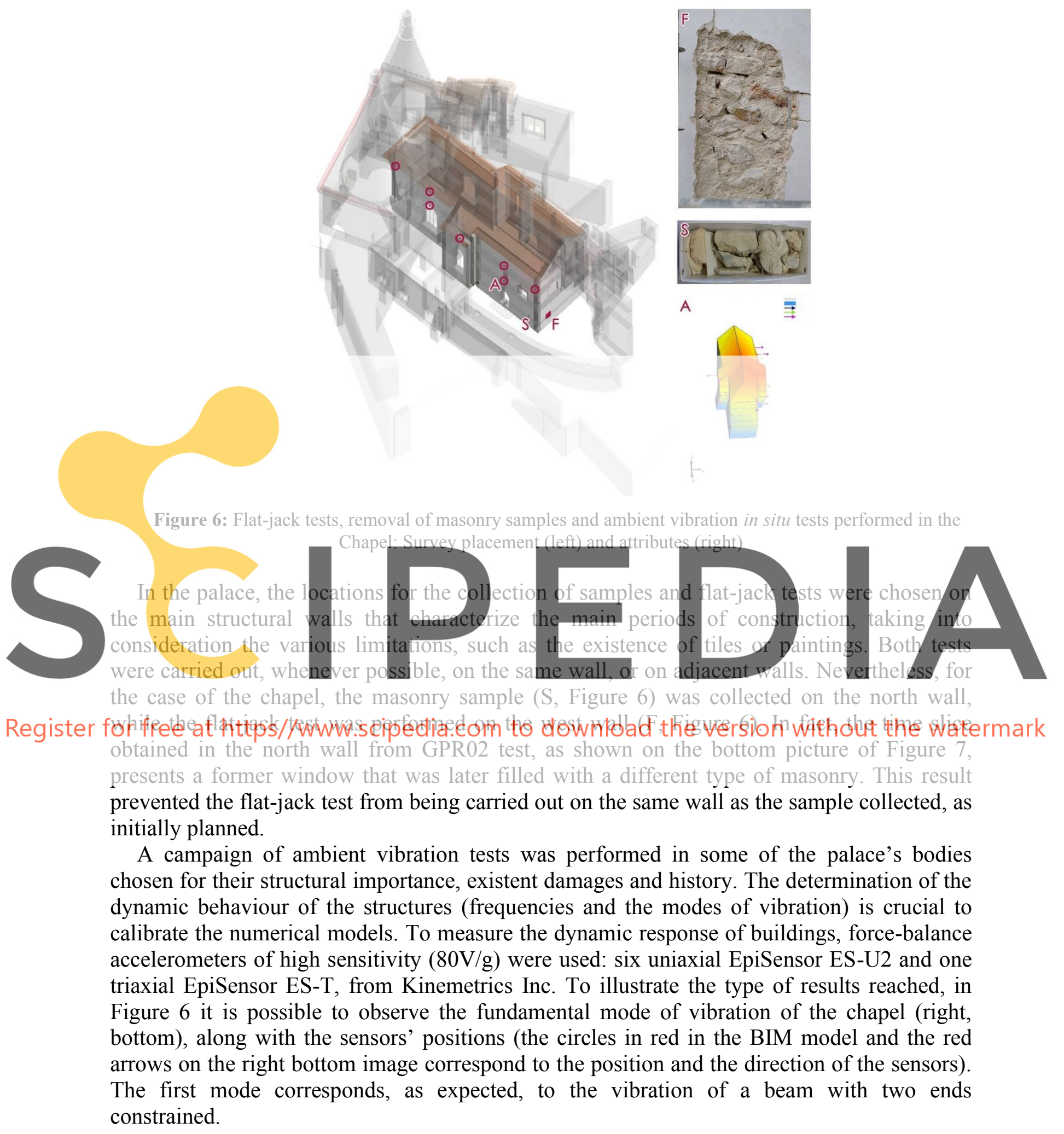



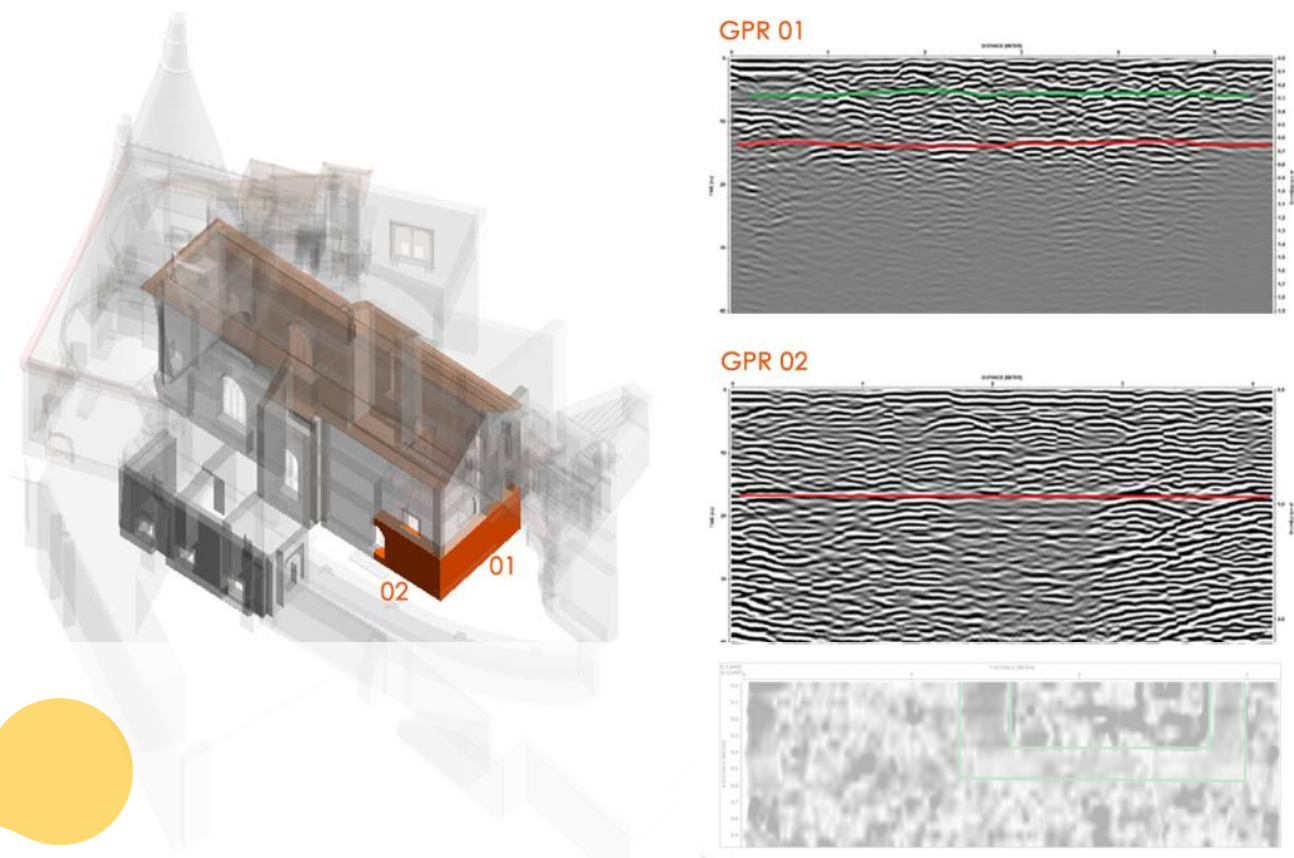

Figure 7: GPR in-situ tests performed in the Chapel: Survey placement (left) and attributes (right)

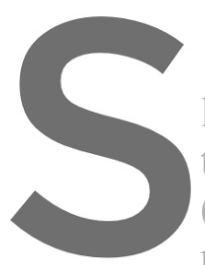

With the GPR survey leaves of stone with

the exterior leaf. On the

(west wall), the limit of th

presented in red. The results of the north wall
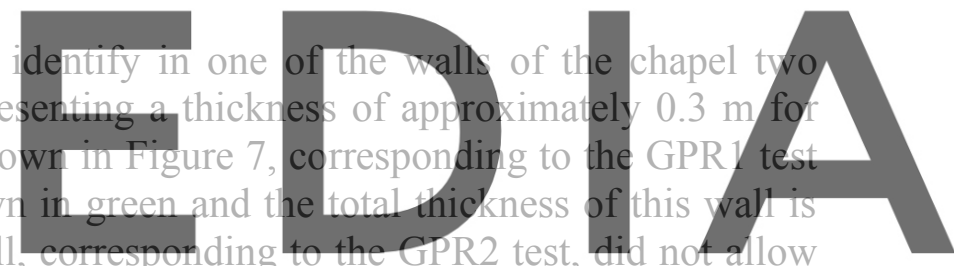

to obtain reliable data on the internal structure of the wall. It was only identified a total

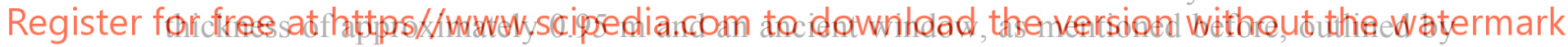
stones of 0.3-0.4 $\mathrm{m}$ width that was later infilled with a material that is different from the rest of the wall.

\section{RESULTS}

The final point cloud dataset of the chapel is presented in Figure 8 (left), after cleaning the noise data from features both outside of the palace (e.g. surrounding buildings) and the interior non-structural and non-architectural elements (e.g. furniture). The complete H-BIM model is presented in Figure 8 (right), and in it is possible to access different type of data for individual elements or sections of the building, including horizontal or vertical sections (Figure 9). The detailed geometric representation obtained allows to develop adequate structural models for the seismic assessment, for the identification of vulnerabilities and to recommend eventual future mitigation strategies. 

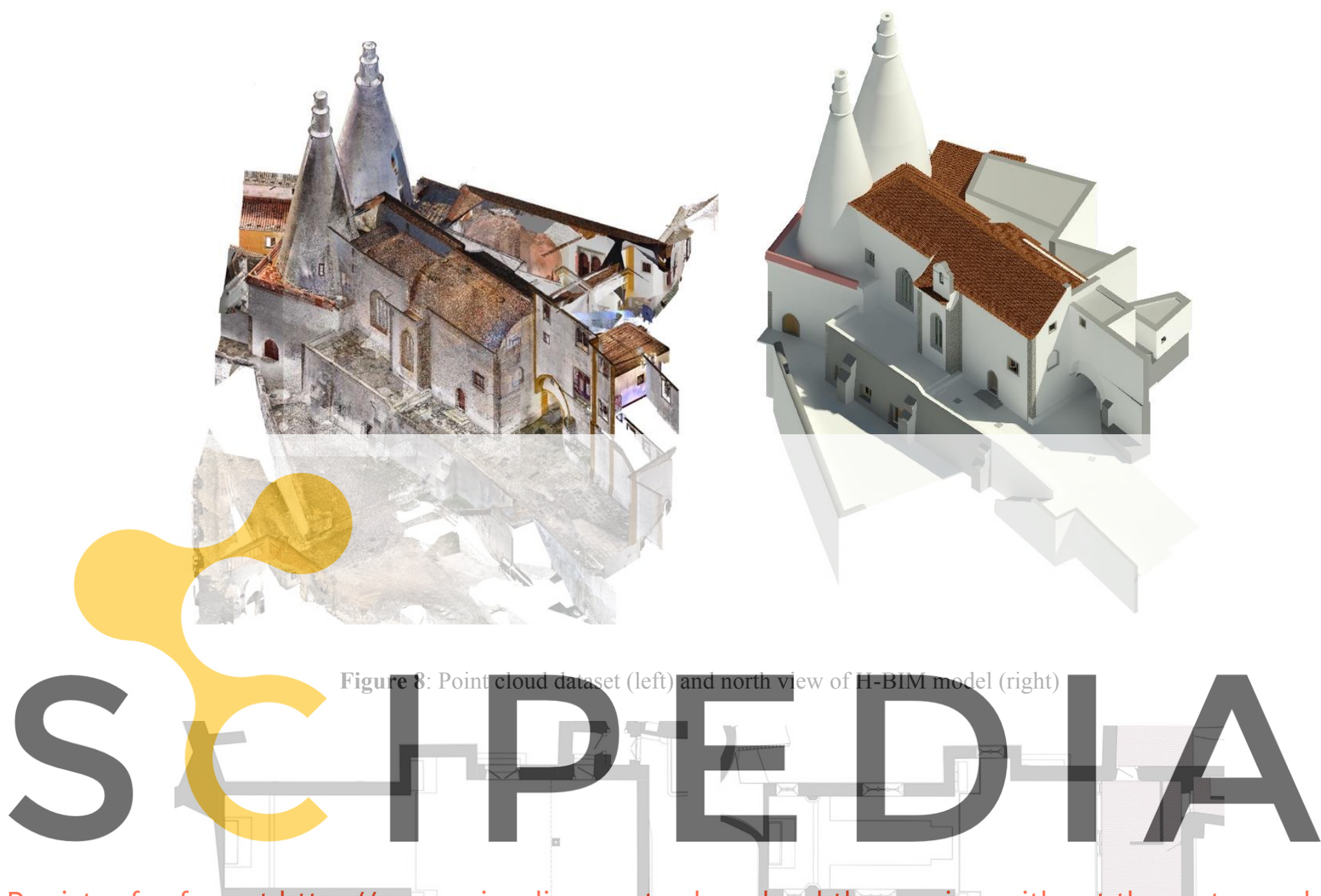

Register for free at https//www.scipedia.com to download the version without the watermark
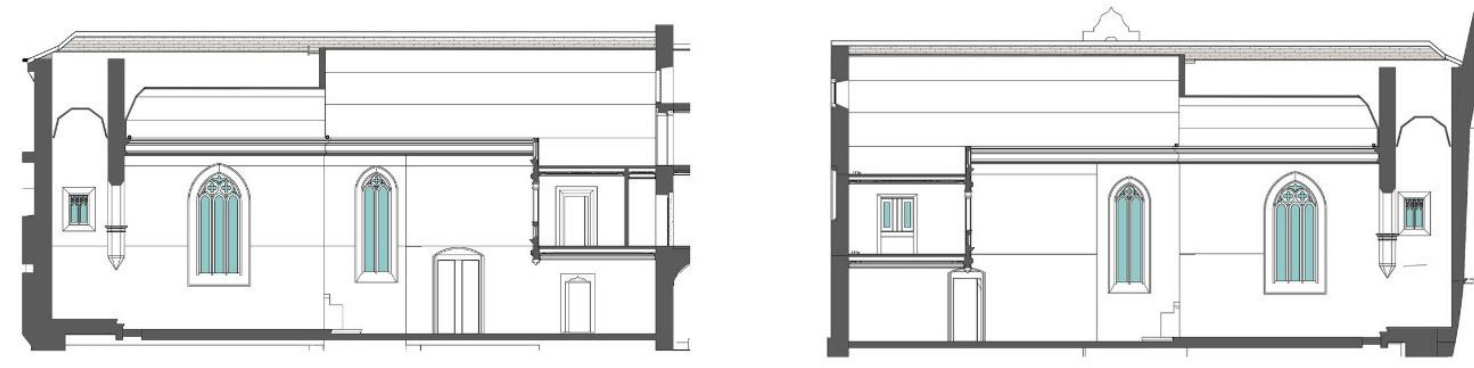

Figure 9: Horizontal sections (top) and vertical sections (bottom) and of the BIM model of the chapel

The H-BIM was used to develop the building's 3D numerical model in the 3Muri [6] software. Lately, the results of the structural analyses performed in 3Muri were introduced in the H-BIM model. The results of ambient vibration tests and flat-jack tests together with the performance of modal analysis and using as reference the values given in Italian Standard [7] 
allowed the correct mechanical characterization of the materials, which was after linked to the H-BIM model. Figure 10 illustrates the calibrated mechanical properties of the masonry walls of the chapel.
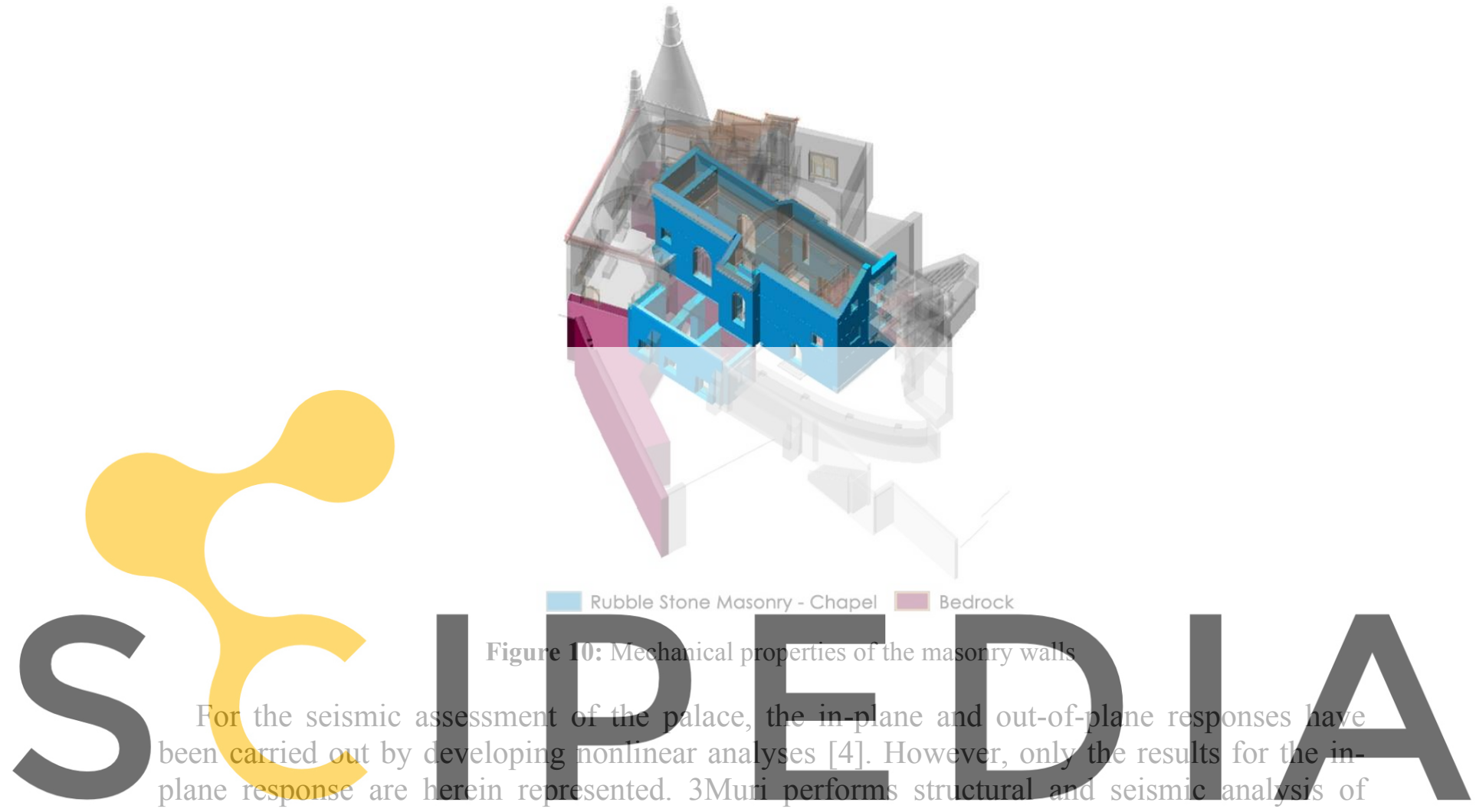

masonry buildings, is based on the equivalent frame modelling (EFM) approach and allows

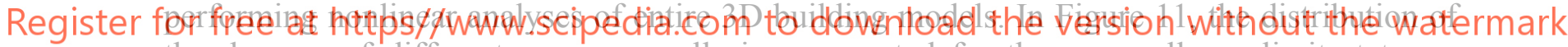

the damage of different masonry walls is represented for the near-collapse limit state, as

required for monuments according to Part 3 of Eurocode 8 [8]; this extreme situation allows

an easy and clear identification of the most vulnerable structural masonry walls and the type of behaviour (shear or bending) which will control their performance. The results shown in Figure 11 were obtained having performed nonlinear static analyses in the two main directions of the chapel [4] and present a combination of the worst outcome of each analysis.

The representation of the distribution of damage in masonry walls through the H-BIM model facilitates spatial reading and enables easy identification of the most vulnerable structural elements and thus the type future interventions to be implemented in the seismic retrofit stage. 


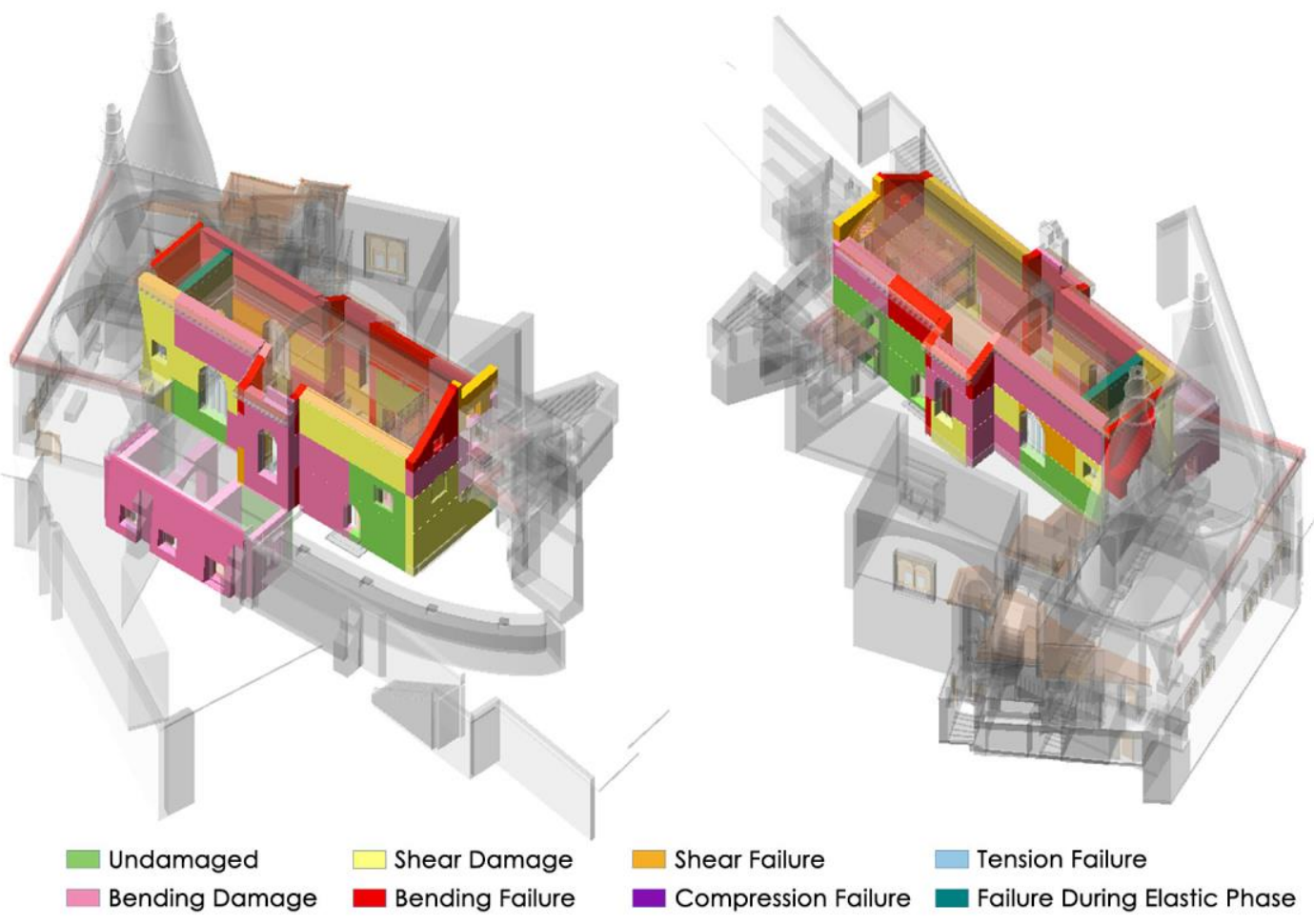

Figure 11: Distribution of damage in masonry walls at a near collapse limit state: north view (left) and south view (right)

\section{FINAL COMMENTS}

The usage of BIM solutions represents a step forward into the management of $\mathrm{CH}$ construction, leading to a high level of integration of the information processes that facilitates the flow of data and its continuous revising. This way, a unique platform integrates all geometric and attribute data, and makes it accessible to technicians, architects, historians and public authorities, which is of the utmost importance to coherently manage such spaces.

In this study, a detailed BIM of the National Palace of Sintra, Portugal, has been implemented starting from the points cloud obtained with a laser scanner survey. This work is herein described, and the results obtained for one of the buildings of the palace, the chapel, are presented as illustrative of the model established. The developed system constitutes the central resource for the historical documentation, the description of materials, construction stages, structural analysis, additional technological aspects, and other information from further inspections such as experimental in-situ tests. The latter was obtained for the characterization of the structural elements to then perform the seismic assessment of the palace. The BIM model defined incorporates all this information either in embedded attributes or as external links. Also, the highly detailed geometric representation based on the laser scanning survey allows producing adequate structural models that have been used in the seismic vulnerability assessment procedures and integrates the results of these structural analyses into the BIM database. As such, the main contribution of this work is the presentation of the applicability of the combined use of the attribute storage and geometry database capabilities of heritage BIM through two-way information exchange with structural 
analysis software, feeding a circular and continuous dataflow. The information structure that was implemented in the developed solution is prepared to support planning, cost assessment, sustainability evaluation, structural retrofit interventions and building management activities.

The detailed geometric survey of the palace is a valuable resource for management, as it enables future analyses of the building that require comparisons with the current state, e.g., in the result of man-made actions or natural hazardous events.

Additional research will focus on the automatic transformation of the BIM model into an accurate 3D equivalent frame model (EFM), and on the assessment of the usability of the developed system as a keystone for the management of the palace. Currently, the link between the autonomous BIM and EFM system elements follows a loose coupling approach, where data structures are not shared, and information processing is done via external files. According to the process followed, there is no automation in the data sharing and information processing between the two software components. Thus, developments on this particular topic deserve future attention.

A survey on the capacities of the system to cover the needs of data access, update and exchange are also considered for the near future.

Acknowledgements. This project is coordinated by IST and funded by Parques de SintraMonte da Lua, S.A.. The authors thank the company Parques de Sintra - Monte da Lua S.A. for supporting this research. The authors also thank Daniel Silva for facilitating the communication between the research team and the National Palace of Sintra management. Lastly, the first author would like to acknowledge the financial support of the Portuguese Foundation for Science and Technology (Ministry of Science and Technology of the Republic of Portugal) through a PhD scholarship [grant number SFRH/BD/145571/2019].

\section{REFERENCES}

[1] Osello, A., Lucibello, G., Morgagni, F., HBIM and virtual tools: a new chance to preserve architectural heritage buildings, Buildings (2018) 8(1), 12; doi: 10.3390/buildings 8010012

[2] Bruno, N., Roncella, R. A restoration oriented HBIM system for cultural heritage documentation: the case study of Parma Cathedral. In: The International Archives of the Photogrammetry, Remote Sensing and Spatial Information Sciences, vol. XLII-2, (2018), ISPRS TC II Mid-term Symposium “Towards Photogrammetry 2020”, Riva del Garda, Italy, 2018. doi: 10.5194/isprs-archives-XLII-2-171-2018

[3] Godinho, M., Machete, R., Ponte, M., Falcão, A.P., Gonçalves, A., Bento, R., BIM as a resource in heritage management: An application for the National Palace of Sintra, Portugal, Journal of Cultural Heritage (2019), Elsevier. doi: 10.1016/j.culher.2019.11.010

[4] Ponte, M., Bento, R., Silva, D.V., A multi-disciplinary approach to the seismic assessment of the National Palace of Sintra, International Journal of Architectural Heritage, Conservation (2019), Analysis, and Restoration, Taylor \& Francis. doi: $10.1080 / 15583058.2019 .1648587$

[5] Bento, R., An Interdisciplinary Approach to the Seismic Assessment of Built Cultural Heritage: Case Studies in Lisbon and Outskirts, Structural Analysis of Historical 
Constructions (2019), Springer International Publishing, Editors: Rafael Aguilar, Daniel Torrealva, Susana Moreira, Miguel A. Pando, Luis F. Ramos, Print ISBN: 978-3-31999440-6, Electronic ISBN: 978-3-319-99441-3

[6] 3MURI (version 11.5). 2018. Italy: S.T.A. Data

[7] MIT. Circolare n. 617 del 2 febbraio 2009. Istruzioni per l'Applicazione Nuove Norme Tecniche Costruzioni di cui al Decreto Ministeriale 14 gennaio 2008 (2009). (in Italian)

[8] CEN. NP EN 1998-3: Eurocódigo 8 - Projecto de estruturas para resistência ao sismo. Parte 3: Avaliação e Reabilitação de edifícios. Instituto Português da Qualidade. European Committee for Standardization, (2017). Retrieved from www.iso.org/iso/foreword.html. (in Portuguese) 